The relative dexterity of the legs was tested in a number of cases, but a press of other duties prevented further experiments in this direction. From the tests made, however, it is obvious that there is no direct relation of the relative dexterity of the legs to the bias in walking.

From these experiments it is evident that the calise of the observed unconscious bias in walking is not to be found in the mechanical proportions, or relative strength, or dexterity (?) of the legs.

The application of well-established physiological principles will, however, furnish a ready explanation of the phenomena in question.

The co-ordination of the voluntary muscles is the exclusive prerogative of the nervous system and the senses are important factors in all movements involving a definite direction. The muscles of locomotion when called into action under ordinary conditions, as when walking in a straight line, are co-ordinated or brought into an orderly correlation, by impulses conveyed to the nervous centres through the afferent or sensory nerves, but when in the dark, or in a mist, or when one is blindfolded, the senses are not available as a guide to direction, the co-ordinating nervous mechanism is dormant, and a divergence from a right line is made to the right, or the left, from a lack of equilibrium in the action of the efferent or motor nerves.

In several of the trials, to determine the bias in walking, interruptions occurred before the course was completed, by the opening of the door at the side of the hall and the talking, in a low tone, of the visitors, which served as a guide in orientation, and the curve made before the interruption was suddenly corrected to a line parallel to the meridian.

In all of the trials the greatest care was taken to prevent the senses from gaining clues to the right direction.

Unconscious bias in walking is obviously the result of vital activities involving complex actions and reactions in the nervous system, which may be clearly defined in general terms, while the details of the obscure changes taking place in the nervous mechanism cannot, in the present state of our knowledge, be fully traced. Moreover, it is evident that the phenomena in question must be studied from the same stand-point of other biological processes which cannot be explained or expressed by purely physical or chemical conditions.

Massachusetts Agricultural College, Amherst, Mass., April 7

\section{The Flora of Canada}

THE review by Mr. J. G. Baker in your last number (p. 242) of the second part of Prof. Macoun's "Catalogue of Canadian Plants" prompts me to send you a few notes on some of the features of the flora of Canada, which I had an unusual opportunity of observing last autumn under the guidance of Prof. Macoun in the neighbourhood of Ottawa, and again in the magnificent railway trip given to members of the British Association by the Canadian Pacific Railway Company from Lake Superior to Kicking-Horse Pass in the Rocky Mountains.

Throughout Eastern Canada and the Eastern United States the European botanist is struck with the strange intermingling, in the wayside flora, of forms new and strange with those familiar by every roadside and in every hedge-bank in England. Away from human habitatiuns the flora is almost altogether novel, but near houses, introduced purposely or accidentally, the English weeds are rivalling and even supplanting the native. I was particularly struck with noticing the vegetation of the grass lawn by the hotel on the Catskill Mountains at an elevation of about 3000 feet. It consisted almost entirely of the same species as yout would expect to find in similar situations at a lower altitude in the old country: Achillea Millefolium, Daucus Carota, Plantago major, Chenopodium album, Cnicus lanceolatus, $\& c$, most or all of them importations. Elsewhere, in the east, you find docks, milfoil, thistles, shepherd's purse, jostling Asters, Asclepiases, Amaranthuses, Solidagus, and other peculiarly. American weeds, Exactly the same thing is taking place with introduced animals. I was staying at a farmhouse in Ontario, not far from Niagara, and was told that the English housesparrow made his appearance there about three years since, and is already as abundant as in England, and a terrible nuisance. Some English plants, however, like our daisy and primrose, seem to refuse to naturalise them elves to the American soil and climate.

Everywhere the lines of the railways are marked by the advent of the foreigner. As Prof. Asa Gray said at Montreal, even English weeds now travel by express train. It is most interesting, in travelling westwards over the vast continent, to note the gradual disappearance of European and the unrivalled supremacy of American types. But it is not only westwards that the tide of fioral conquest makes its way. A fellow-traveller of our party had the good fortune to gather, near Port Arthur on Lake Superior, where we were detained twenty-four hours by stress of weather, a grass, Beckmannia eruceformis, 300 miles east of any locality previously recorded

Although in the main the indigenous American flora is altogether different specifically from ours, yet there are exceptions. I am not now speaking of the Alpine flora of the Rocky Mountains, which agrees to a wonderful extent generically, and even specifically, with the flora of the Alps, Pyrenees, or Grampians. Covering the vast extent of ground from the eastern sea-board to the Rockies are a few species undoubtedly indigenous and absolutely identical with European and even English forms. I may mention three illustrations taken from widely-separated natural orders-Polentilla fruticosa, Campanula rotundifolia, and Linaria vulgaris. How to reconcile these facts with any theory accounting for the geographical distribution of species on the face of the earth it is difficult to say.

Even more interesting are those cases where American and European plants are regarded as belonging to the same species, but where there is a certain difference difficult to define, but recognisable at a glance. To take, again, three examples:Among the most cosmopolitan of ferns are Osmunda reyalis and Pteris aquilina. Abundant throughout Canada, there is yet, in both cases, a general habit by which they are at once distinguished from the English forms. Again, the American Plantago major is all but indistinguishable from the English wayside weed. And yet, it is said, American horses know the difference. Prof, Macoun is contemplating a visit to Europe next year, when one of his special objects will be to compile an account of these closely-allied but yet distinct eastern and western forms. It is possible that such a comparative list-and it could not be in better hands-may throw some light on some of the many still unsolved problems connected with the evolution and distribution of species.

ALFRED W. BENNETT

\section{The Fauna of the Seashore}

In addition to the instances from the Molluscan class mentioned in the interesting letter from $\mathrm{Mr}$. Arthur $\mathrm{R}$. Hunt (NATURE, pp, 243-4), as illustrating-after Prof. Moseley's most valuable contribution-." the variety of method exhibited by the littoral famna in resisting wave-currents," may be mentioned one of a higher class among the fishes-viz., the common smooth blenny (Blennius pholis).

No one who has hunted for this pretty little fish in rock-pools, or who has kept it in an aquarium, can have failed to notice its remarkable adaptation to the ever-varying environment of the littoral zone. The angular form of the head and smooth, mucous-covered body enable it readily to burrow within the smallest crevices of the rocks, to prevent its being washed ashore when the tide is coming in, and to prevent its being carried into deep water when the tide is going out, where it would reaclily fall a prey to rapacious fishes, as it has apparently little power to swirn freely to a distance, not needing to do so in shallow water. Its peculiarly modified ventral fins, forming almost anterior limbs, enable it to cling securely not only to weeds and rocks, but even to perpendicular surfaces, for similar purposes to those above stated, while its beautifully-marked body-o splashed dark and light greens-seems to be a case of mimicry of the sea-weeds which afford it protection from its natural ene mies among its own class and those of the higher Crustacea. An allied deep-sea genus (Anharricas, the wolf-fish), whose ancestor was probably a littoral blenny, has the ventral fin entirely wanting, and the head is round, for the obvious reason; that it does not need to cling to surfaces nor to burrow in crevices. This fish is, however, compensated by a formidable array of sharp teeth to protect it from its natural enemies. In the aquarium no fish, in my experience, is so readily tamed as the smooth blenny, so as to allow it to be handled, or exhibit such a high degree of piscine intelligence, arising doubtless from long education, both inherited and acquired; in the varying environment which is its habitat. A specimen now in my aquarium daily avails itself of the advantage of the dry ledge of the slope-backed tank "to get a mouthful of fresh air," while 